\title{
Монобутираты и монопропионаты в рационах цыплят-бройлеров улучшают их продуктивность и срок хранения охлажденных тушек
}

Гончаров А.Т., соискатель кафедры зоогигиены и птицеводства им. А.К. Даниловой

Московская государственная академия ветеринарной медицины и биотехнологии - МВА имени К.И. Скрябина

Аннотация: Влияние кормобой добабки, содержащей моноэриры глицерина (5\% 1-монобутирата и 20\% 1монопропионата) совместно с абсорбентом токсинов (43\% переработанного бентонита), на продуктивность цыплят-бройлеров и срок хранения их охлажденных тушек исследовано на 5 группах бройлеров кросса «Арбор Айкерс» (3000 голов б группе, 1-37 дни жизни). Контрольная группа 1 получала комбикорма 6 соответствии с рекомендациями для кросса; опытные группы 2-5 получали с теми же комбикормами изучаемую добавку $\mathcal{6}$ дозах 0,5; 1,0, 1,5 и 2,0 кг/m корма. После убоя тушки хранили охлажденными 6 течение 10 дней для определения срока хранения. Установлено, что по средней живой массе 6 37 дней группы 3, 4 и 5 достоверно превосходили контроль на 5,7; 9,7 и 12,6\% соответственно, по конверсии корма - на 3,2-3,9\%. Сохранность поголовья во всех опьтных группах была быше, чем 6 контрольной, на 1,372,03\%, европейский индекс эфрективности выращивания бройлеров (ЕРЕF) б группах 2-5 был быше контроля на 22, 40, 58 и 69 ед. соответственно. По выходу и химическому составу грудных мыши группы существенно не различались. Органолептическая (Визуальная) оценка качества мяса при хранении тушек и динамика микробной обсемененности (КМАФАнМ) глубинных слоев мяса показали, что при использовании изучаемой добабки в дозах 1,0, 1,5 и 2,0 кг/т срок хранения охлажденных тушек бройлеров можно безопасно продлить с 6 до 8-9 суток.

Ключебые слова: альфа-моноглицериды, 1-монобутират, 1-монопропионат, абсорбент токсиноб, продуктивность иыплят-бройлеров, срок хранения охлажденных тушек.

Введение. В настоящее время к препаратам, способным заменить кормовые антибиотики, относят моноглицериды жирных кислот [1]. В природе моноглицериды встречаются очень редко. Их получают путем этерификации молекулы глицерина одной молекулой той или иной жирной кислоты. Оба компонента нейтральные, следовательно, и новая молекула, как и ее составляющие, полностью метаболизируется в организме [2].

Многие исследования доказывают, что 1-моноглицериды в несколько раз эффективнее в борьбе с патогенными бактериями, чем органические кислоты или их соли. Это объясняется тем, что молекулы 1-моноглицеридов имеют прочные ковалентные связи между молекулой глицерина и жирной кислотой, и в желудочно-кишечном тракте (ЖКТ) они практически не диссоциируют, даже при очень высоких значениях $\mathrm{pH}$ среды кишечника, в отличие от органических кислот с их слабой ионной связью, которые быстро диссоциируют и проявляют свою бактерицидную активность, в основном, только в верхних отделах пищеварительной системы [3].

В зависимости от типа присоединенной к молекуле глицерина жирной кислоты, моноглицериды имеют различную степень антимикробной активности. При этом наибольший антибактериальный эффект имеют соединения, в которых жирная кислота присоединена к молекуле глицерина к крайней гидроксильной группе - это так называемые альфа- или 1-моноглицериды. В частности, монэфиры глицерина с короткоцепочечными жирными кислотами обладают наибольшей активностью в отношении Грам-отрицательных патогенных бактерий, таких как E. coli, Salmonella spp. и др. Механизм их бактерицидного действия заключается в том, что 1моноглицериды, проникая через ворсинки кишечника, циркулируют в лимфатической и кровеносных системах и не расщепляются в печени ферментом эстеразой, так как в жидкой среде 1-моноглицерид принимает линейную форму (в виде «карандаша»), а эстераза в печени может гидролизовать только более крупные молекулы. 
1-моноглицериды, двигаясь в жидкой среде «глицериновой стороной» вперед, легко проникают через клеточную мембрану бактериальной клетки, так как молекула глицерина является питательным субстратом для патогенных бактерий, и они легко пропускают ее внутрь себя. При этом молекула глицерина прочно ковалентно связана с молекулой жирной кислоты, которая также проникает внутрь бактериальной клетки вслед за глицерином. Внутри патогенной бактерии 1-моноглицерид расщепляется на составные части - глицерин и органическую жирную кислоту, и при этом выделяются ионы водорода, которые резко понижают уровень рH плазмы бактериальной клетки. В свою очередь, бактериальная клетка, пытаясь восстановить рН-градиент и удалить избыточные ионы водорода, парализующие ее жизнеспособность, тратит на этот процесс колоссальное количество энергии, что и приводит к прекращению ее деления, патогенности и, в конечном итоге - к гибели. Одними из наиболее эффрективных соединений против Грамотрицательных патогенных бактерий являются монобутират, моноэфир глицерина с масляной (С:4) кислотой, а также монопропионат, моноэфир глицерина с пропионовой (С:3) кислотой $[4,5]$.

Антибактериальные препараты нового поколения, позволяющие высокоэффективно снизить патогенную микрофлору не только в ЖКТ, но и в конечной продукции - в мясе и яйце, находят все более широкое применение [6-10]. Наличие в кормах моноглицеридов короткоцепочечных жирных кислот обеспечивает снижение количества патогенных бактерий в ЖКТ и в организме животных и птиц в целом $[2,9,11,12]$.

Но патогенные бактерии также вырабатывают эндотоксины и экзотоксины. Некоторые виды патогенных бактерий (например, сальмо- неллы и др.) при разрушении в организме выделяют эндотоксины. Поэтому становится актуальным поиск и исследование современных более эффективных антибактериальных препаратов нового поколения, способных значительно снизить отрицательное влияние патогенных бактерий на производственные показатели выращивания бройлеров и повысить каче-ство готовой продукции.

В нашем исследовании в составе рациона, наряду с данными эффективными антибактериальными добавками (глицерина 1-монобутират и 1-монопропионат), был также использован абсорбент токсинов - переработанный бентонит, который в определенной степени снижает токсикацию организма птицы. В исследовании также изучали возможности продления сроков годности тушек бройлеров при хранении в охлажденном виде.

Материал и методика исследований. Для проведения опыта бройлеров кросса «Арбор Айкерс» в суточном возрасте разделили на 5 групп (1 контрольная и 4 опытные) по 3000 голов в каждой и выращивали до 37 дней жизни. Условия выращивания и питательность комбикормов для всех групп были одинаковыми и соответствовали рекомендациям для данного кросса.

Цыплята 1 группы служили контролем и получали комбикорма основного рациона, составленного согласно рекомендациям по выращиванию данного кросса.

В комбикорма для цыплят 2, 3, 4 и 5 опытных групп дополнительно в основной рацион включали кормовой препарат, содержащий 1монобутират (5\%) и 1-монопропионат глицерина (20\%), абсорбент токсинов (переработанный бентонит, 43\%) и наполнитель (кремнезем). Дозировка препарата в опытных группах 2-5 была 0,5; $1,0,1,5$ и 2,0 кг/т корма соответ- ственно.

В опыте учитывали живую массу птицы, количество поедаемого корма, сохранность поголовья. При убое у 6 голов из каждой группы (по 3 петушка и 3 курочки) определяли массу потрошеной тушки, грудных и ножных мышц, а также химический состав грудных мышц.

Со дня убоя тушки бройлеров хранили согласно ГОСТ [13] в течение 10 суток для проведения органолептической и микробиологической оценки сроков годности мяса из глубоких слоев охлажденной тушки при хранении.

Качественное состояние мяса охлажденных тушек при хранении оценивали по комплексу органолептических показателей в соответствии с ГОСТ [14]: внешний вид, цвет, запах, консистенция, сочность и др. Микробиологический статус мяса из глубоких слоев охлажденных тушек оценивали по количеству мезофильных аэробных и факультативно анаэробных микроорганизмов (КМАФАнМ) согласно требованиям $[15,16]$.

В период хранения тушек визуальная оценка порчи мяса проводилась по следующим критериям: бледно-желтая поверхность тушки, с присутствием слизи, сероватый оттенок жира с зелеными пятнами, ослизнение серозных оболочек грудно-брюшной полости, чрезмерная дряблость или влажность мышечной ткани, присутствие гнилостного запаха.

Результаты исследований и их обсуждение. Внесение в рационы кормовой добавки, содержащей 1-монобутират и 1-монопропионат совместно с абсорбентом токсинов, оказало положительное влияние на показатели продуктивности цыплятбройлеров (табл. 1).

Наиболее высокая продуктивность бройлеров была в 3, 4 и 5 опытных группах. По средней живой массе в 37 дней цыплята этих групп достоверно опережали контрольную группу на 5,7; 9,7 и 12,6\% соотве- 
Таблица 1. Продуктивность цыплят-бройлеров, получавших в рационах 1-моноэфиры глицерина и абсорбент токсинов

\begin{tabular}{lccccc} 
Показатели & \multicolumn{5}{c}{ Группа } \\
& $\mathbf{1 ( \kappa )}$ & $\mathbf{2}$ & $\mathbf{3}$ & $\mathbf{4}$ & $\mathbf{5}$ \\
\hline Сохранность поголовья, \% & 96,23 & 97,60 & 98,13 & 98,13 & 98,26 \\
\hline Живая масса при убое, г & 2127,9 & $2179,7^{*}$ & $2248,7^{*}$ & $2335,9^{* *}$ & $2395,1^{* *}$ \\
\hline $\begin{array}{l}\text { Затраты корма на 1 кг прироста } \\
\text { живой массы, кг }\end{array}$ & 1,57 & 1,55 & 1,52 & 1,51 & 1,51 \\
\hline Убойный выход, \% & 74,2 & 74,5 & 74,8 & 75,1 & 75,1 \\
\hline $\begin{array}{l}\text { Европейский индекс эффектив- } \\
\text { ности выращивания (ЕРЕF), йод. }\end{array}$ & 352 & 370 & 392 & 410 & 421 \\
\hline
\end{tabular}

Различия с контролем достоверны при: *P<0,05; **P<0,01

тственно. Сохранность поголовья во всех опытных группах была выше, чем в контрольной, на 1,37-2,0\%. Затраты кормов на 1 кг прироста живой массы в группах 3, 4 и 5 были ниже контроля на 3,2-3,9\%.

По показателям убойного выхода лучшие результаты (выше контроля на 0,9\%) получены в опытных группах 4 и 5. Во всех опытных группах также получили лучшие значения европейского индекса эффективности выращивания бройлеров (EPEF), которые были выше уровня контроля на 22, 40, 58 и 69 единиц соответственно.

При исследовании массы грудных и ножных мышц, а также содержания питательных веществ в грудных мышцах цыплятбройлеров достоверных различий между группами по уровню сухого вещества, белка, жира и золы не выявили.
В опытных группах также улучшились качественные показатели охлажденных тушек в период хранения (табл. 2). Оценка органолептических показателей мяса показала различия между группами в зависимости от применяемых дозировок кормовой добавки. На 7-е сутки хранения мясо в 1 контрольной и 2 опытной группах по комплексу органолептических показателей начало портиться, в то время как мясо бройлеров 3, 4 и 5 групп еще соответствовало показателям свежего мяса.

На 8-е сутки мясо в группах 1 и 2 уже испортилось, в 3 группе оно начало портиться, а в опытных группах 4 и 5 соответствовало показателям свежего мяса до 10-го дня хранения.

Показатели общей микробной обсемененности мяса из глубинных слоев охлажденных тушек 1 и

\begin{tabular}{|c|c|c|c|c|c|}
\hline \multirow{2}{*}{$\begin{array}{c}\text { Срок } \\
\text { хранения }\end{array}$} & \multicolumn{5}{|c|}{ Группа } \\
\hline & $1(\mathbf{k})$ & 2 & 3 & 4 & 5 \\
\hline & \multicolumn{5}{|c|}{ Органолептическая оценка } \\
\hline 5 суток & \multicolumn{5}{|c|}{ Соответствует свежему мясу } \\
\hline 6 суток & \multicolumn{5}{|c|}{ Соответствует свежему мясу } \\
\hline 7 суток & Начало порчи & Начало порчи & \multicolumn{3}{|c|}{ Соответствует свежему мясу } \\
\hline 8 суток & Порча мяса & Порча мяса & $\begin{array}{c}\text { Начало порчи } \\
\text { Порча мяса }\end{array}$ & $\begin{array}{l}\text { Соответствует } \\
\text { свежему мясу }\end{array}$ & $\begin{array}{l}\text { Соответствует } \\
\text { свежему мясу }\end{array}$ \\
\hline 9 суток & -- & -- & - & $\begin{array}{l}\text { Соответствует } \\
\text { свежему мясу }\end{array}$ & $\begin{array}{l}\text { Соответствует } \\
\text { свежему мясу }\end{array}$ \\
\hline 10 суток & -- & -- & & Порча мяса & Порча мяса \\
\hline & (КМАФАнМ м & $\begin{array}{r}\text { Микробиол } \\
\text { яса из глубоких }\end{array}$ & $\begin{array}{l}\text { огическая оценк } \\
\text { слоев охлаждег }\end{array}$ & $\begin{array}{l}\text { ка } \\
\text { нной тушки, КО }\end{array}$ & $E / \Gamma)$ \\
\hline 5 суток & не более 10 & не более 10 & не более 10 & не более 10 & не более 10 \\
\hline 6 суток & $8,3 \times 10^{4}$ & $3,5 \times 10^{4}$ & $9,2 \times 10^{3}$ & $8,7 \times 10^{3}$ & $7,1 \times 10^{3}$ \\
\hline 7 суток & $5,0 \times 10^{5}$ & $4,7 \times 10^{5}$ & $7,5 \times 10^{4}$ & $2,4 \times 10^{4}$ & $1,1 \times 10^{4}$ \\
\hline 8 суток & -- & -- & $2,0 \times 10^{5}$ & $6,2 \times 10^{4}$ & $4,0 \times 10^{4}$ \\
\hline 9 суток & -- & -- & -- & $1,9 \times 10^{5}$ & $1,6 \times 10^{5}$ \\
\hline 10 суток & -- & -- & -- & $2,5 \times 10^{6}$ & $6,8 \times 10^{5}$ \\
\hline
\end{tabular}

2 групп превысили допустимые нормативы по КМАФАнМ на 7-е сутки хранения. На 8-й день хранения в опытной группе 3 этот показатель был равен допустимой норме, а в опытных группах 4 и 5 показатели микробной обсемененности мяса были ниже допустимых норм. В опытных группах 4 и 5 превышение предельно допустимой бактериальной обсемененности мяса было отмечено только на 10-е сутки хранения.

Результаты теста микробиологического состояния охлажденного мяса птицы при хранении согласуются с его органолептической оценкой и служат предпосылкой к увеличению сроков годности мяса в охлажденном состоянии с 6 до 8-9 суток для тушек бройлеров, которым включали в состав рационов антибактериальный препарат, содержащий 1-монобутират, 1монопропионат и абсорбент токсинов, в дозах 1,0; 1,5 и 2,0 кг/т корма.

Заключение. Результаты исследования показывают, что введение в рацион цыплят-бройлеров антибактериального препарата, содержащего 1-монобутират и 1-монопропионат глицерина в комплексе с абсорбентом токсинов (переработанным бентонитом), позволяет:

- увеличить живую массу птицы на 5,7-12,6\%;

- улучшить сохранность поголовья цыплят-бройлеров на 1,372,0\%;

- улучшить конверсию корма на 1,2-3,9\%;

- повысить европейский индекс эффективности выращивания бройлеров (EPEF) на 22-69 единиц;

- повысить убойный выход на 0,3-0,9\% без отрицательного влияния на мясные качества тушек и химический состав мышечной ткани;

- продлить срок годности охлажденных тушек с 6 до 8-9 суток по показателям органолептической и бактериологической оценки мяса. 
Лучшими продуктивными и постубойными качествами отличались цыплята-бройлеры, получавшие в рационах изучаемый препарат в дозах 1,0; 1,5 и 2,0 кг/т корма.

\section{Литература}

1. Porter, C.J.H. Lipids and lipid-based formulations: optimizing the oral delivery of lipopohilic drugs / C.J.H. Porter, N.L. Trevaskis, W.N. Charman // Nature Rev. Drug Discov. - 2007. - V. 6. P. 231-248.

2. Гончаров, А. Моноглицерид: возможности получения дополнительно до двух поросят за опорос // Комбикорма. - 2016. - №1 . - С. 88-89.

3. Вопольская, Е.А. Значение органических кислот в обменных процессах у сельскохозяйственной птицы / Е.А. Вопольская, В.В. Кравченко, Л.Н. Скворцова // Научное обеспечение агропромышленного комплекса: Сб. статей. - Краснодар, 2016. - С. 154-157.

4. Kabara, J.J. Antimicrobial agents derived from fatty acids // J. Amer. Oil Chem. Soc. 1984.- V. 61, No 2. - P. 397-403.

5. Dufour, M. Characterization of monolaurin resistance in Enterococcus faecalis / M. Dufour, J.M. Manson, P.J. Bremer, J.-P. Dufour, G.M. Cook, R.S. Simmonds // Appl. Environ. Microbiol. 2007. - V. 73, No 17. - P. 5507-5515.

6. Дорина, Д.С. Ветеринарносанитарная оценка мяса птицы при выявлении Pseudomonas aeruginosa // Д.С. Дорина, Е.В. Павлова // Мат. XIX Междунар. конф. ВНАП. - Сергиев Посад, 2018. - С. 591-594.

7. Егоров И.А. Современные подходы к кормлению птицы // Птицеводство. 2014. - №4. - С. 11-16.

8. Козак, С.С. Снижение контаминации тушек бройлеров путем использования в корме пробиотиков / С.С. Козак, С.А. Барышников // Птица и птицепродукты. 2009. - №3. - С. 32-34

9. Гончаров А.Т. Использование монолаурина В кормлении цыплятбройлеров / А.Т. Гончаров, Т.Н. Хамидуллин // Птица и птицепродукты. 2012. - №3. - С. 30-32.

10. Фисинин В.И. Методические наставления по использованию в комбикормaх для птицы новых биологически активных, минеральных и кормовых добавок / В.И. Фисинин, Т.М. Околело- ва, И.А. Егоров [и др.]. - Сергиев Посад: ВНИТИП, $2011 .-91$ с.

11. Гончаров А. Новое поколение кормовых добавок в России // Комбикорма. - 201 8. - №1 . - С. 84-86.

12. Гончаров А. Альфа-моноглицериды эффективно разрушают патогенную микрофлору // Комбикорма. - 2020. №1 . - С. 114 -1 16.

13. ГОСТ 31962-2013. Мясо кур (тушки кур, цыплят-бройлеров и их части). Технические условия.

14. ГОСТ 31470-2012. Мясо птицы, субпродукты и полуфабрикаты из мяса птицы. Методы органолептических и физико-химических исследований.

15. ГОСТ 50396.1-2010. Мясо птицы, субпродукты и полуфабрикаты из мяса птицы. Метод определения количества мезофильных аэробных и факультативно-анаэробных микроорганизмов.

16. МУК 4.2. 1847-04. Санитарноэпидемиологическая оценка обоснования сроков годности и условий хранения пищевых продуктов.

Для контактов с автором: Гончаров Артур Талгатович E-mail: 122333artur@gmail.com

\title{
The Effects of Glycerol 1-Monobutyrate and 1-Monopropionate in Diets for Broilers on the Productive Performance and Shelf Life of Chilled Carcasses
}

\author{
Goncharov A.T.
}

\author{
Moscow State Academy of Veterinary Medicine \& Biotechnology
}

\begin{abstract}
Summary: The effects of a feed additive containing glycerin monoesters (5\% of 1-monobutyrate and 20\% of 1monopropionate) and toxin binder (43\% of processed bentonite) on the productive performance and shelf life of chilled carcasses were studied on 5 treatments of Arbor Acres broilers (3,000 birds per treatment, 1-37 days of age). Control treatment was fed standard diets according to the recommendations of the breeding company; treatments 2-5 were fed the same diets supplemented with the additive (500,1000, 1500, and 2000 ppm). After the slaughter the carcasses were stored chilled for 10 days to determine the shelf life period. It was found that average live bodyweight at 37 days of age in treatments 3, 4, and 5 was significantly higher in compare to control by 5.7 ( $p<0.05) ; 9.7$ and 12.6\% ( $p<0.01)$, respectively; feed conversion ratio in these treatments was higher by 3.2-3.9\%. Mortality in all treatments fed the additive was higher by 1.37-2.03\% in compare to control; European Production Efficiency Factor in treatments 2-5 was higher in compare to control by 22, 40, 58 and 69 points, respectively. No significant differences were found in the yield and chemical composition of breast meat. Visual assessment of meat quality and the dynamics of total microbial count in deep layers of the chilled carcasses during the storage indicated that the shelf life of the carcasses of broilers fed the additive in doses 1000, 1500, and 2000 ppm can be safely prolonged from 6 to 8-9 days.
\end{abstract}

Key words: alpha-monoglycerides, 1-monobutyrate, 1-monopropionate, toxin binder, productive performance in broilers, shelf life of chilled carcasses. 